Accelerator Department

BROOKHAVEN NATIONAL IABORATORY

Associated Universities, Inc.

Upton, L.I., N.Y.

AGS DIVISION TECHNICAL NOTE

No. 12

J.C. Schuchman

February 18, 1966

\title{
REPORT ON TRIP TO CAMBRIDGE ELECTRON ACCELERATOR
}

I am reporting on the trip made by D. Hoober and myself to the C.E.A. The purpose of this trip was to investigate the methods used for sealing the vacuum chambers in the CEA, with the possibility of applying some of their techniques at AGS.

Vacuum Chamber Seals: The standard vacuum chambers were origina11y sealed with aluminum we (see CEA-TM-44). This design compresses a .081 diameter (alum. alloy $1100 \mathrm{~T}-0$ ), solid wire ring to a thickness of .060-in. between two flat stainless steel flanges machined to a 32 micro-inch finish. The squeeze depth is controlled with a .060 thick retaining ring which also locates the aluminum ring. Stainless steel bolts are used to "make-up" the joint. A sealing force of $1200 \mathrm{lbs}$ per linear inch of gasket is used. Through normal use, the unprotected sealing faces of the flanges become scratched and sealing with aluminum becomes more difficult. Lead wire gaskets were tried as were indium wire seals. The "creep" associated with indium caused minor leaks (flanges had to occasionally be retightened). The indium also adheres to the flanges causing a cleaning problem. Lead gaskets were successfully used and are now in general use on the machine. They have had no problems with "creep" or with lead sticking to the flanges. Lead wire (100\% pure) .060-in. diameter is compressed to .012/.015 thick. Strict torquing of the bolts is not required to make a leak tight seal. To make a lead gasket the wire is cut to length and the ends fused together using a hand torch. The restrictions on the joint are not too critical since the gasket is compressed to one quarter of its original size. The formed wire ring is aligned between the flat chamber flanges with locating studs and then tightened. No retaining ring is used.

Valves: Isolation valves on the CEA are a11 metal bellows sealed. The gate seat is lead sealing against a raised ring on the inside of the stainless valve body (basic knife edge design). The valve has to be torqued. (30-70 ft. 1bs) to produce the required sealing force.

Remarks: The use of lead in a vacuum system is not new or unique. It has a vapor pressure of $10^{-9}$ at $300^{\circ} \mathrm{C}$ and a melting point of $327^{\circ} \mathrm{C}$ making it suitable for general use in a high vacuum system. Although we have not had the problem of indium sticking to the flanges as reported by CEA and others, it would be wise for use to try lead plating the metal 0-rings. This should also help in handling and storing the rings and possibly even in the plating.

Since CEA has not found the "creep" of lead seals excessive, to the point of requiring retightening, we should consider using lead wire gaskets for odd shaped seals such as target box covers to estimate the outgassing from the rubber seals.

Distribution: V. Buchanan, C. Gould, J. Grisoli, D. Hoober, C. Lasky, I. Polk 
Accelerator Department

BROOKHAVEN NATIONAL I.ABORATORY

Associated Universities, Inc.

Upton, L.I., N.Y.

AGS DIVISION TECHNICAL NOTE

No. 11

Th. Sluyters

February 4, 1966

PROGRESS REPORT (4) CONCERNING HIGH GRADIENT COLUMN

The duoplasmatron in the present preinjector continues to perform reliable with an averaged beam current of around $75 \mathrm{~mA}$ after the column. Harold Wroe thinks that the cathode attachment will soon be in its final state.

Harold took a bunch of emittance measurements at $750 \mathrm{keV}$ for various conditions and geometries of the extractor region of the source; he is still in the process of evaluating his results. An interesting feature anyhow, is that with a small expansion cup ( $\phi=1 \frac{1}{2} \mathrm{~mm}$ instead of $4 \mathrm{~mm}$ ), an important higher brilliance $\left(\sim 8 \times 10^{8} \mathrm{~mA} / \mathrm{cm}^{2} \mathrm{rad}^{2}\right)$ could be obtained, maintaining the same column output current. To determine the maximum column output (which is now $115 \mathrm{~mA}$ ), he plans to insta 11 a solenoid with large inner diameter just behind the column.

The duoplasmatron with large cup has been installed in the rig; unfortunately oscillations ( $\pm 15 \%$ of the peak value) have been observed on the output, but none on the discharge current, which was inherent in previous results with the old source. The only difference was the anode exit hole (0.025-in.), which could not be made larger due to the absence of cooling around the leak. A quick check of some larger cup sizes on Harold's rig proved that the size of the exit hole was indeed important. A cathode air-vacuum lock is in the workshop.

\section{Accelerating Column}

A column has been assembled with one set of voltage dividers (bananas) and spark gaps. Vacuum has been obtained as 1 ow as $6 \times 10^{-7} \mathrm{~mm}$ (meter indication). 
Vincent Kovarik's RDI power supply is now running more or less reliably at $600 \mathrm{kV}$. The rectifiers are still a weak part; 1ife tests with modified Machlett tubes will start soon. The HV bushing (an unshielded Sames cable) and the connections with the measuring dome stood $600 \mathrm{kV}$ during short trials. HV tests of dome and column are in progress.

The vital parts for the inner structure and assembling are ready; however, Bill Schneider has to modify the adaptor of the source, so that the anode can reach the extractor at closer distances than originally planned. His measuring box should be ready as soon as possible, (ultimate date - middle of March!).

Final cabling by Bob Lockey's people should be finished soon. A $150 \mathrm{kV}$ power supply will be installed in the equipment dome; it can be used either to increase the voltage up to $750 \mathrm{kV}$ or as a stand-by in case of lower limitation in RDI, bushings, etc.

After some modifications of Rudy Damm's solenoid, the theoretical magnetic field has been obtained; significant asymmetries $(\sim 5 \%$ of axis field value) within an effective core of 2 -in. were observed over short distances on both ends of the solenoid. An improved version with twice the number of turns per unit length than the original one will diminish the above asymmetries to a smaller figure.

Dick Amari's $750 \mathrm{kV}$ automatic emittance unit is more or less designed.

The $50 \mathrm{MeV}$ emittance unit is in the assembling status. There is some lack of technicians in this building period.

Attached you will find a time schedule of the HV tests, etc.
cc: R. Amari
R. Damm
V. Kovarik
R. Larson
R. Lockey
V. Racanie11o
W. Schneider
A. van Steenbergen
H. Wroe

TS/ah 
TIME SCHEDULE

\begin{tabular}{|c|c|c|c|c|c|}
\hline & $\begin{array}{l}\text { Feb } \\
7-11\end{array}$ & $\begin{array}{l}\text { Feb } \\
14-18\end{array}$ & $\begin{array}{l}\text { Feb } \\
21-25\end{array}$ & $\begin{array}{l}\text { Feb. -March } \\
28=4\end{array}$ & $\begin{array}{l}\text { March } \\
7-11\end{array}$ \\
\hline RDI - dome - column HV tests & & & & . & \\
\hline Installation Ti-electrodes & & & & & \\
\hline HV tests column and electrodes & & & & & \\
\hline $\begin{array}{l}\text { Installation ion source, emittance box, } \\
\text { belt, freon cooling, solenoid, second } \\
\text { set of voltage dividers }\end{array}$ & & . & & & \\
\hline
\end{tabular}

